\title{
MATERNAL PARENTING IN SINGLE AND TWO-PARENT FAMILIES IN SOUTH AFRICA FROM A CHILD'S PERSPECTIVE
}

\author{
Nicolette Vanessa Roman \\ University of the Western Cape, Bellville, South Africa
}

\begin{abstract}
Single mothers are often perceived and depicted as being ineffective parents in comparison to their married counterparts, but this may not always be the case. A sample consisting of 245 children ( $72 \%$ in married mother families and $28 \%$ in single mother families) between 10 and 12 years $(M=11)$ including $64 \%$ females and $36 \%$ males participated in the study. The aim in this study was to compare children's perceptions of their mothers' parenting within single and married families. The results indicate that mothers were perceived as using more autonomy-supportive than psychologically controlling parenting practices. There were no significant differences between children's perceptions of maternal parenting in single and married families.
\end{abstract}

Keywords: parenting, family structure, single mothers, autonomy support, psychological control.

Divorce rate trends in South Africa are consistent with international divorce rates. According to Statistics South Africa (2008), the past decade has seen a marked increase in divorce rates within the different racial groups, with African groups increasing from $18 \%$ to $35 \%$, Indian/Asian groups from $5 \%$ to $6 \%$, and Colored groups (persons from a mixed descent) from $1 \%$ to $3 \%$. The White groups declined from $40 \%$ to $33 \%$ and this decline is considered high given the fact that this is a minority group in South Africa. Furthermore, couples who had divorced and had children under the age of 18 years accounted for $57 \%$ of the

Nicolette Vanessa Roman, Department of Social Work, University of the Western Cape, Bellville, South Africa.

Appreciation is due to reviewers including: Müdriye Yildiz Biçakçi, Ankara University, Içaydinlik, Ankara, Turkey, Email: mudriyebicakci@yahoo.com

Please address correspondence and reprint requests to: Nicolette Vanessa Roman, University of the Western Cape, Private Bag X17, Bellville 7535, South Africa. Email: nroman@uwc.ac.za 
sample. These results imply that more children are being raised in a single parent family, usually a single mother.

Single mothers are stereotypically described as deviant, with married mothers perceived as the "standard" against which other mothers, for example, never married, widowed, or divorced mothers, are rated (Ganong \& Colman, 1995; Johnson, 2003). In addition, single mothers are considered to create dysfunctional children and families (Matlin, 2000; O'Barr, Pope, \& Wyer, 1990; Phoenix \& Woollett, 1991; Ribbens, 1994; Richardson, 1993). In light of these stereotyped standards which mothers have to attain, many single mothers are challenged psychosocially in comparison to their married counterparts. Single mothers are at a greater socioeconomic disadvantage than their married counterparts (Ceballo \& McLoyd, 2002; Franz, Lensche, \& Schmitz, 2003; Olson, Ceballo, \& Park, 2002; Whitehead \& Holland, 2003). They are more likely to have fewer household resources, lower income, to rent rather than own a house, and to be unemployed, poor, and suffer from low self-esteem. Single mothers are more likely to be very insecure economically resulting from low earning capacity, lack of child support, and insufficient/inadequate public benefits. Additionally, single mothers are thought to be more punitive and have a more authoritarian parenting style (Bigner, 1998). These disparities create an environment that is stereotypical and therefore encourages the perception of differences between single and married mothers.

Researchers have suggested that single and married mothers may not be as different as they are perceived to be. For instance, single and married mothers have similar personality characteristics, overall psychological well-being, and are similarly vulnerable and reactive to stressors (Avison, Ali, \& Walters, 2007; Greitemeyer, 2009). Kendig and Bianchi (2008) found that single mothers do not spend significantly less time with their children than do married mothers. If they do spend less time with their children then this is purely because of their social structural location. These structural locations could be caused by differences in socioeconomic status, employment, education, age of children, and exposure to different stressful and distressing environments. Single mothers may not have the support of other family members. These circumstances may contribute significantly to the quality of life, social functioning, and context of the mother-child relationship.

The quality of child care or parenting is frequently compromised due to the length of time spent working in order to support children in single mother families. Single mothers may not have the choice of being a stay-at-home parent if they are the sole providers in a family (Kendig \& Bianchi, 2008). Thus, single mothers may often suffer from strain and chronic fatigue which could result in ineffective parenting compared to parenting by married mothers (Bank, Forgatch, Patterson, \& Fetrow, 1993; Florsheim, Tolan, \& Gorman-Smith, 1998; Segal-Engelchin 
\& Wozner, 2005). The belief is that families in which two parents are present provide more stable environments for children compared to single parent homes because two parents can assist each other in rearing children. Furthermore, shared parenting rather than single parenting may increase the likelihood of positive developmental outcomes for children (Bauserman, 2002). Researchers indicate that optimal mother-child interaction in single-parent families is predicted by fewer stressful life events, reduced social contact, increased parenting support, and the hours of maternal employment (Crockenberg, 1988; Grolnick, Benjet, Kurowski, \& Apostoleris, 1997). In comparison, optimal mother-child interaction in two-parent families is predicted by fewer stressful life events, satisfaction with emotional support, and the availability of household help. Social contacts, household help, and employment differentially predict mother-child interactions in both single and two-parent families (Hashima \& Amato, 1994; Weinraub \& Wolf, 1983).

According to self-determination theory (SDT), an individual will function optimally and be self-determined if environments are autonomy-supportive rather than psychologically controlling (Deci \& Ryan, 1985). Parent-child interactions could provide an environment which is either psychologically controlling or autonomy-supportive. When mothers are psychologically controlling children will perceive their mothers as attempting to control their behavior, feelings, and thoughts in an attempt to deter the child's individuation (Barber, 1996; El-Sheikh, Hinnant, Kelly, \& Erath, 2010). Psychological control has been shown to result in overt aggression in both boys and girls (Loukas, Paulos, \& Robinson, 2005), as well as lowered self-esteem levels, higher dropout rates at school, maladaptive learning attitudes, and ill-being (Bean, Bush, McKenry, \& Wilson, 2003; Van Steenkiste, Zhou, Lens, \& Soenens, 2005). Psychological control has also been found to be related to incompetence and bulimia (Blodgett Salafia, Gondoli, Corning, Bucchianeri, \& Godinez, 2009).

Autonomy-supportive parenting encourages strong parent-child relationships and parents are highly valued. Thus, mothers who are autonomy-supportive are more likely to consider the child's views in age-appropriate decision-making, provide warmth, structure, support, and are involved in their children's activities (Grolnick, Deci, \& Ryan, 1997). Children, who are raised by parents who are autonomy-supportive, are well-adjusted, competent, and have self-confidence and higher levels of self-esteem (Deci \& Ryan, 1985; Grolnick, 2003). Additionally, children are more adaptive in their learning attitudes and strategies, have academic self-motivation and success, higher well-being, are self-regulated, and act prosocially (Chirkov, Ryan, Youngmee, \& Kaplan, 2003; Gagné, 2003; Van Steenkiste et al., 2005). Thus, while autonomy-supportive parenting is more positive and enhances child well-being, psychologically controlling parenting encourages more negative parent-child relationships (Barber, 1996; Grolnick, 2003; Soenens, 2006). 
Most studies have been focused on the effects of family structure on child behavior or general well-being of children in single and married families, thus being more focused on outcomes. Given the debate about single and married mother-child interactions, the aims in this study were: (1) to determine the extent to which children perceived their mothers to be autonomy-supportive and psychologically controlling; and (2) to compare children's perceptions of their mothers' parental practices in single and married families. The aim in this study was to provide further insight into the similarities and differences between maternal parenting practices in single and two-parent families.

\section{METHOD}

\section{Participants}

The sample of this study consisted of 245 mother-child dyads. The mean age of the children was 11 years, with $36 \%$ male and $64 \%$ female participants. The majority of the participants were from the Colored ${ }^{1}(57 \%)$ racial group. The sample consisted of married (72\%) and single mothers (28\%) from both high $(68 \%)$ and low (32\%) socioeconomic backgrounds.

\section{INSTRUMENT}

A questionnaire with two sections was developed for the study. The first section incorporated demographic information regarding age, socioeconomic status of mothers, grade of participants, and so on. The second section consisted of the Perceptions of Parents Scale (POPS; Grolnick, Deci, \& Ryan, 1997) and the Parental Psychological Control Questionnaire (Barber, 1996). The POPS provides an indication of the optimal parenting context for children. Children's perceptions are appraised in terms of the degree to which their parents are involved and autonomy-supportive in their lives. The scale has 22 items, 11 for the mother and 11 for the father. The items form autonomy-supportive and involvement subscales for both mothers and fathers. Only the items pertaining to mothers were used in this study. Children as young as eight years old are able to answer the questionnaire and responses are provided on the questionnaire. Children were asked to choose an item which very closely resembled their mothers. An example of an item is:

a. My mother never has enough time to talk to me.

b. My mother usually does not have enough time to talk to me.

\footnotetext{
During the Apartheid era, in South Africa, people were classified according to a particular racial group. There were four classified groups, that is, Black, White, Indian/Asian, and Colored. Colored people were individuals who were from a mixed descent.
} 
c. My mother sometimes has enough time to talk to me.

d. My mother always has enough time to talk to me.

The items are scored and reverse scored on a scale of 1 to 4 with 1 being low and 4 being high. Subscales were computed by averaging all the items within the given subscale for each participant. Mothers were considered supportive and involved when children scored 3 and 4 on the POPS. The Cronbach's alpha for this study was .72 .

The Parental Psychological Control Questionnaire was developed by Barber (1996). This questionnaire is an 8-item scale used to assess mothers' use of psychological control. Children responded by choosing responses on a 3-point Likert scale with $1=$ not like her; $2=$ somewhat like her; and $3=$ a lot like her . Examples of items included: "My mother is a person who is always trying to change how I feel or think about things". "My mother is a person who changes the subject whenever I have something to say". The higher the scores the more controlling mothers are perceived to be. Participants were asked to circle their response. The alpha reliability was .73 .

\section{Procedure}

The Western Cape Education Department granted permission for the study to be conducted at the schools. Mother-child dyads were recruited to participate in the study. Consent forms were issued to children for mothers to complete. Once the consent forms were received group questionnaire administration occurred. These groups consisted of 15 to 20 groups of children. Child participants were informed about the purpose of the study and provided their assent to voluntarily participate before the actual administration of the questionnaire. The completion of the questionnaire was anonymous and participants' confidentiality was guaranteed. The administration of the questionnaire took approximately 15 minutes and was completed in the presence of a trained fieldworker.

Data were analyzed using descriptive statistics, which indicated children's prevalent perceptions with regard to how their mothers parent. Differences in single and married mother parenting practices were tested using independent $t$ tests.

\section{RESULTS AND DISCUSSION}

Previous researchers have shown parenting to be either positive or negative. Autonomy-supportive and involved parenting is considered to be a more positive approach to parenting, while psychological control is more negative. When parenting is autonomy-supportive and children are involved in family activities, parents provide structure, warmth, and participate in their children's activities, especially at school. Children raised in homes where parents are autonomy- 
supportive and involved are more likely to have increased psychological well-being, are competent and are generally well-adjustment (Joussemet, Koestner, Lekes, \& Landry, 2005).

Psychologically controlling parenting has been described as sinister, invasive, and inhibitive (Barber, 1996). This approach to parenting takes over the child's thinking, feeling, and behavioral processes to the extent that children are unable to make decisions. Children of parents who are psychologically controlling are inclined to feel incompetent, anxious, depressed, and have low self-esteem (Blodgett Salafia, et al., 2009; Doyle \& Markiewicz, 2005). Additionally, they are more likely to be aggressive (Loukas et al., 2005), drop out of school, be disinterested in learning, and have general ill-being (Grolnick, 2003; Soenens, 2006).

In the current study, results (see Table 1) show that children perceived their mothers to be autonomy-supportive and involved rather than psychologically controlling. These findings suggest that the majority of the children considered their mothers to be autonomy-supportive and involved. This indicates that mothers are perceived as providing warmth, structure, competence, acknowledgements of feelings and thoughts of children, and opportunities to participate in family decision-making. Similar results have been obtained in previous studies (Soenens \& Van Steenkiste, 2005; Soenens et al., 2007).

TABLE 1

Perceptions of Maternal Parenting Practices Between Children of Single and MARRIED Mothers

\begin{tabular}{|c|c|c|c|c|c|}
\hline Maternal parenting & $\begin{array}{l}\text { Total group } \\
\text { of children } \\
n=245\end{array}$ & $\begin{array}{c}\text { Children of } \\
\text { married mothers } \\
n=178\end{array}$ & $\begin{array}{c}\text { Children of } \\
\text { single mothers } \\
n=67\end{array}$ & $t$ & $p$ \\
\hline Psychological control & $(3.60)$ & $11.90(3.72)$ & $12.28(3.25)$ & -.73 & .46 \\
\hline Autonomy-support & $2.70 \quad(.61)$ & $2.70 \quad(.61)$ & $2.70 \quad(.63)$ & -.06 & .96 \\
\hline Involvement & $3.40 \quad(.61)$ & $3.40 \quad(.61)$ & $3.37 \quad(.62)$ & .36 & .72 \\
\hline
\end{tabular}

The data gained in this study were also used to compare children's perceptions of single and married mother parenting practices. Some previous researchers have found differences in perceptions regarding single and married mothers (Ceballo \& McLoyd, 2002; Franz et al., 2003; Olson et al., 2002; Whitehead \& Holland, 2003). Furthermore, single mothers are inclined to be punitive and harsh in their parenting approaches (Bigner, 1998), are responsible for the children's delinquent behaviors (Matlin, 2000; Ribbens, 1994), and are therefore ineffective parents (Bank et al., 1993; Segal-Engelchin \& Wozner, 2005). 
In the current study, the results show that children of single and married mothers had similar perceptions of maternal parenting practices. There were no significant differences (see Table 1) between the groups. This finding is supported by previous studies in which it is suggested that there are no significant differences between single and married mothers (Avison et al., 2007; Greitemeyer, 2009; Kendig \& Bianchi, 2008). The results of this study suggest that regardless of marital status, children perceived their mothers to be more autonomy-supportive and less psychologically controlling.

There could be reasons why no significant difference was found between the groups. Perhaps single and married mothers have support, such as social contacts and household help, in raising their children (Hashima \& Amato, 1994; Weinraub \& Wolf, 1983). Another reason could be the fact that their children are older and therefore less dependent on maternal care. Furthermore, there may be social and cultural practices which could increase the positive relationships between mothers and children. However, further research is needed to examine these possibilities.

\section{CONCLUSION}

The results of this study suggest that children perceive their mothers' parenting practices to be autonomy-supportive and involved. Furthermore, this result was consistent for children of single and married mothers, which suggests that marital status does not account for parenting practices. However, the present study has limitations. In this study only maternal parenting practices reported by their children were examined. Future researchers could: (1) conduct studies using the variables used in the current study with fathers; (2) compare mothers of younger and older children in order to determine if there would be a difference between single and married mothers; (3) compare reports of parenting practices by both parent and child; and (4) include demographic variables such as socioeconomic status as another variable for comparison.

\section{REFERENCES}

Avison, W. R., Ali, J., \& Walters, D. (2007). Family structure, stress, and psychological distress: A demonstration of the impact of differential exposure. Journal of Health and Social Behavior, 48(3), 301-317.

Bank, L., Forgatch, M. S., Patterson, G. R., \& Fetrow, R. A. (1993). Parenting practices of single mothers: Mediators of negative contextual factors. Journal of Marriage and the Family, 55, 371-384.

Barber, B. K. (1996). Parental psychological control: Revisiting a neglected construct. Child Development, 67(6), 3296-3319.

Bauserman, R. (2002). Child adjustment in joint-custody versus sole-custody arrangements: A meta-analytic review. Journal of Family Psychology, 16(1), 91-102. 
Bean, R. A., Bush, K. R., McKenry, P. C., \& Wilson, S. M. (2003). The impact of parental support, behavioral control, and psychological control on the academic achievement and self-esteem of African American and European American adolescents. Journal of Adolescent Research, 18(5), 523-541.

Bigner, J. J. (1998). Parent-child relations: An introduction to parenting. New York: MacMillan.

Blodgett Salafia, E. H., Gondoli, D. M., Corning, A. F., Bucchianeri, M. M., \& Godinez, N. M. (2009). Longitudinal examination of maternal psychological control and adolescents' selfcompetence as predictors of bulimic symptoms among boys and girls. International Journal of Eating Disorders, 42(6), 422-428.

Ceballo, R., \& McLoyd, V. C. (2002). Social support and parenting in poor, dangerous neighborhoods. Child Development, 73(4), 1310-1321.

Chirkov, V., Ryan, R. M., Youngmee, K., \& Kaplan, U. (2003). Differentiating autonomy from individualism and independence: A self-determination theory perspective on internalization of cultural orientations and well-being. Journal of Personality and Social Psychology, 84(1), 97110.

Crockenberg, S. B. (1988). Stress and role satisfaction experienced by employed and nonemployed mothers with young children. Journal of Family and Economic Issues, 9(2), 97-110.

Deci, E. L., \& Ryan, R. M. (1985). Intrinsic motivation and self-determination in human behavior. New York: Plenum.

Doyle, A. B., \& Markiewicz, D. (2005). Parenting, marital conflict and adjustment from early-to mid-adolescence: Mediated by adolescent attachment style? Journal of Youth and Adolescence, 34(2), 97-110.

El-Sheikh, M., Hinnant, B., Kelly, R. J., \& Erath, S. (2010). Maternal psychological control and child internalizing symptoms: Vulnerability and protective factors across bioregulatory and ecological domains. Journal of Child Psychology and Psychiatry, 51(2), 188-198.

Florsheim, P., Tolan, P., \& Gorman-Smith, D. (1998). Family relationships, parenting practices, the availability of male family members, and the behavior of inner-city boys in single-mother and two-parent families. Child Development, 69(5), 1437-1447.

Franz, M., Lensche, H., \& Schmitz, N. (2003). Psychological distress and socio-economic status in single mothers and their children in a German city. Social Psychiatry and Psychiatric Epidemiology, 38(2), 59-68.

Gagné, M. (2003). The role of autonomy support and autonomy orientation in prosocial behavior engagement. Motivation and Emotion, 27(3), 199-223.

Ganong, L. H., \& Colman, M. (1995). The content of mother stereotypes. Sex Roles: A Journal of Research, 32(7/8), 495-512.

Greitemeyer, T. (2009). Stereotypes of singles: Are singles what we think? European Journal of Social Psychology, 39(3), 367-383.

Grolnick, W. (2003). The psychology of parental control: How well-meant parenting backfires. New Jersey: Erlbaum.

Grolnick, W. S., Benjet, C., Kurowski, C. O., \& Apostoleris, N. H. (1997). Predictors of parent involvement in children's schooling. Journal of Educational Psychology, 89(3), 538-548.

Grolnick, W. S., Deci, E. L., \& Ryan, R. M. (1997). Internalization within the family: The selfdetermination theory perspective. In J. E. Grusec \& L. Kuczynski (Eds.), Parenting and children's internalization of values: A handbook of contemporary theory (pp. 135-161). New York: Wiley.

Hashima, P. Y., \& Amato P. R. (1994). Poverty, social support, and parental behavior. Child Development, 65(2), 394-403.

Johnson, D. D. (2003). Invisible mothers: A content analysis of motherhood ideologies and myths in magazines. Sex Roles: A Journal of Research, 49(1/2), 21-33. 
Joussemet, M., Koestner, R., Lekes, N., \& Landry, R. (2005). A longitudinal study of the relationship of maternal autonomy support to children's adjustment and achievement in school. Journal of Personality, 73(5), 1215-1236.

Kendig, S. M., \& Bianchi, S. M. (2008). Single, cohabitating, and married mothers' time with children. Journal of Marriage and Family, 70, 1228-1240.

Loukas, A., Paulos, S. K., \& Robinson, S. (2005). Early adolescent social and overt aggression: Examining the roles of social anxiety and maternal psychological control. Journal of Youth and Adolescence, 34(4), 335-345.

Matlin, M. W. (2000). The psychology of women (4th ed.). New York: Harcourt.

O'Barr, J. F., Pope, D., \& Wyer, M. (1990). Ties that bind: Essays on mothering and patriarchy. Chicago: The University of Chicago Press.

Olson, S. L., Ceballo, R., \& Park, C. (2002). Early problem behavior among children from low-income, mother-headed families: A multiple risk perspective. Journal of Clinical Child and Adolescent Psychology, 31(4), 419-430.

Phoenix, A., \& Woollett, A. (1991). Motherhood: Social construction, politics, and psychology. In A. Phoenix, A. Woollett, \& E. Lloyd (Eds.), Motherhood: Meanings, practices, and ideologies. London: Sage.

Ribbens, J. (1994). Mothers and their children. London: Sage.

Richardson, D. (1993). Women, motherhood, and childrearing. London: Macmillan.

Segal-Engelchin, D., \& Wozner, Y. (2005). Quality of life of single mothers by choice in Israel: A comparison to divorced mothers and married mothers. Marriage and Family Review, 37(4), 7-28.

Soenens, B. (2006). Psychologically controlling parenting and adolescent psychosocial adjustment. Unpublished doctoral thesis, University of Leuven, Belgium.

Soenens, B., \& Van Steenkiste, M. (2005). Antecedents and outcomes of self-determination in three life domains: The role of the parents' and teachers' autonomy support. Journal of Youth and Adolescence, 34, 589-604.

Soenens, B., Van Steenkiste, M., Lens, W., Luyckx, K., Goossens, L., Beyers, W., \& Ryan, R. M. (2007). Conceptualizing parental autonomy support: Adolescent perceptions of promotion of independence versus promotion of volitional functioning. Developmental Psychology, 43(3), 633-646.

Statistics South Africa. (2008). Marriages and divorces. Retrieved May 18, 2010, from www.statssa. gov.za

Van Steenkiste, M., Zhou, M., Lens, W., \& Soenens, B. (2005). Experiences of autonomy and control among Chinese learners: Vitalizing or immobilizing? Journal of Educational Psychology, 97(3), 468-483.

Weinraub, M., \& Wolf, B. M. (1983). Effects of stress and social support on mother-child interactions in single- and two-parent families. Child Development, 54, 1297-1311.

Whitehead, M., \& Holland, P. (2003). What puts children of lone parents at a health disadvantage? Lancet, 361(9354), 289-295. 
